\title{
Models of non-hospice palliative care: a review
}

\author{
Amy Beasley ${ }^{1}$, Marie A. Bakitas ${ }^{1}$, Rebecca Edwards ${ }^{1}$, Dio Kavalieratos ${ }^{2}$ \\ ${ }^{1}$ School of Nursing, University of Alabama at Birmingham, Birmingham, AL, USA; ${ }^{2}$ Section of Palliative Care and Medical Ethics, Division of \\ General Internal Medicine, Department of Medicine, The University of Pittsburgh, Pittsburgh, PA, USA \\ Contributions: (I) Conception and design: All authors; (II) Administrative support: None; (III) Provision of study material or patients: None; (IV) \\ Collection and assembly of data: All authors; (V) Data analysis and interpretation: All authors; (VI) Manuscript writing: All authors; (VII) Final \\ approval of manuscript: All authors. \\ Correspondence to: Amy Beasley. Box 870358, Tuscaloosa, AL 35487-0358, USA. Email: beas1029@uab.edu.
}

\begin{abstract}
Palliative care offers patients with a serious illness and their families access to services that can improve quality of life, mood, and symptoms. However, the term palliative care is often confused with end of life or hospice services limiting its application to persons with chronic illnesses who might benefit. Non-hospice palliative care is a term that is emerging to more accurately reflect the broader care model that palliative care represents. The aim of this review was to identify the characteristics of published nonhospice palliative care interventions. We derived our sample predominantly from a recently published systematic review and meta-analysis and selected studies published since the review. Inclusion criteria were: self-described palliative care intervention studies using randomized designs for participants with lifelimiting illnesses aged 18 years or older. These 38 studies fell into 3 broad categories: primary, specialty, and hybrid models. Common challenges among these models include limited education of generalists, limited reimbursement, and limited access in certain areas. However, increasing palliative care usage has also been associated with increased hospice use and appropriate timing of referrals.
\end{abstract}

Keywords: Non-hospice palliative care; primary palliative care; generalist palliative care; specialty palliative care

Submitted Jan 04, 2018. Accepted for publication Mar 20, 2018.

doi: 10.21037/apm.2018.03.11

View this article at: http://dx.doi.org/10.21037/apm.2018.03.11

\section{Introduction}

Palliative care encompasses chronic illness management, supportive care, and hospice through the end of life (1). The Center to Advance Palliative Care (CAPC) (2) broadly defines palliative care as "specialized medical care for people of any age living with serious illness that focuses on providing relief from the symptoms and stress of serious illness, while improving quality of life at any stage in the disease process". Models of palliative care vary greatly in the current healthcare literature and clinical practice. Despite this, many lay people and healthcare professionals mistakenly equate palliative care with end-of-life or hospice making it difficult to fully appreciate and utilize the broader scope of palliative care services (Table 1). Hence, the term non-hospice palliative care has emerged to better recognize the early introduction of palliative care (5). Non-hospice palliative care can be offered at any time in the illness trajectory and continues as a supportive service for patients receiving curative disease treatment (5). The purpose of this paper is to describe the characteristics of non-hospice palliative care models that have had an impact on individuals with serious illness and their caregivers.

\section{Methods}

We utilized a recently published systematic review and meta-analysis that included randomized clinical trials (RCTs) of palliative care interventions (6). A secondary analysis was carried out and included articles that were related to non-hospice palliative care. Inclusion criteria included self-described palliative care intervention studies using randomized designs and pre-specified patient outcomes and subjects with life-limiting illnesses aged 
Table 1 Non-hospice palliative care $v s$. hospice $(3,4)$

\begin{tabular}{|c|c|}
\hline Palliative care & Hospice \\
\hline May seek aggressive care or therapies simultaneously & No longer seeking aggressive care or therapies \\
\hline May begin at any time in the disease process & Prognosis of 6 months or less to live \\
\hline $\begin{array}{l}\text { May be offered through inpatient, outpatient, community-based, } \\
\text { and telehealth services }\end{array}$ & $\begin{array}{l}\text { May be offered through inpatient and community-based } \\
\text { programs }\end{array}$ \\
\hline Encompasses multidisciplinary team approach to care & Encompasses multidisciplinary team approach to care \\
\hline Focuses on the patient and caregivers & Focuses on the patient and caregivers \\
\hline $\begin{array}{l}\text { Addresses the patient's physical, mental, social, and spiritual well-being } \\
\text { and family bereavement }\end{array}$ & $\begin{array}{l}\text { Addresses the patient's physical, mental, social, and spiritual } \\
\text { well-being and family bereavement }\end{array}$ \\
\hline
\end{tabular}

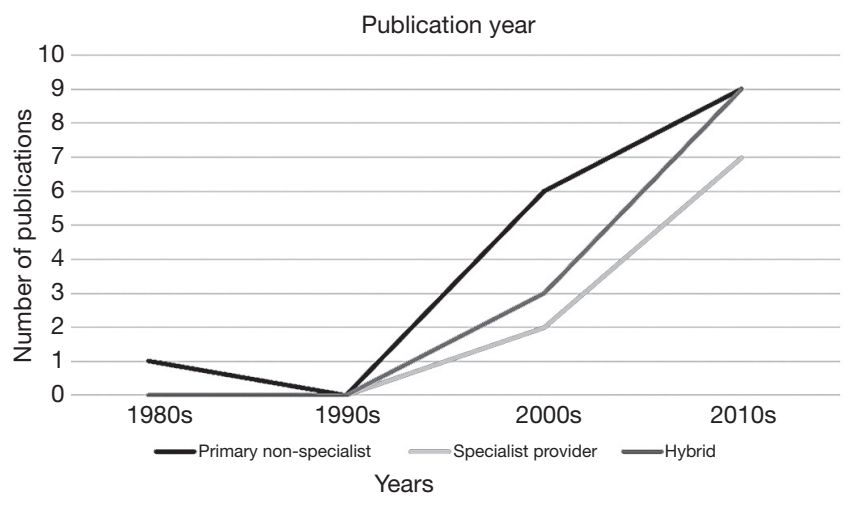

Figure 1 Publications by year.

18 years or older. Exclusion criteria included nonrandomized control trials, a single-focused intervention, a focus only on caregiver outcomes, or studies not related to a life-limiting illness. Pediatric and non-English language articles were also excluded. Titles and abstracts were reviewed for appropriateness from the previous literature search. Of the 43 previously identified randomized control trials (RCTs), nine trials were excluded due to having a hospice/end of life focus. After the initial literature search, we identified three recently published RCTs that met inclusion criteria. A total of 38 articles were identified and included in the synthesis to define the characteristics of non-hospice palliative care.

\section{Results}

The intervention characteristics and key outcomes of each study can be found in a supplementary appendix online (http://apm.amegroups.com/public/addition/apm/suppapm.2018.03.11-1.pdf). Several models of palliative care were identified, with variations of intervention types, providers, and the location of services. The earliest intervention was published in 1989 and the number of published interventions continued to increase with the last included published intervention from 2017 (Figure 1). The included publications were categorized by primary non-specialist interventions $(\mathrm{n}=17)$, specialist provider interventions $(\mathrm{n}=9)$, and hybrid non-specialist/specialist-provider interventions $(n=12)$. Subcategories were based upon the primary location of the intervention. The included interventions had varying time frames and multiple diagnoses. The following diagnoses were included in the studies: cancer $(n=20)$, heart failure $(\mathrm{n}=5)$, dementia/Alzheimer's $(\mathrm{n}=2)$, multiple sclerosis $(\mathrm{n}=1)$, HIV $(n=1)$, and multiple diagnoses $(n=9)$.

\section{Primary non-specialist interventions}

Primary non-specialist interventions included interventions that were provided by healthcare practitioners that had basic palliative care training or providers that were not board-certified palliative care specialists (7). Of the 17 studies that tested primary non-specialist interventions, the models included the following diagnoses: cancer $(n=12)$ and one each in heart failure, dementia/Alzheimer's, HIV, and multiple diagnoses $(n=2)(8-24)$. The subcategories included community home-based $(\mathrm{n}=10)(6-8,12,13,16,18-20,22)$ and ambulatory clinic $(\mathrm{n}=7)(9-11,14,15,17,21)$. No inpatient interventions were identified using a primary non-specialist 
intervention. Community/home-based interventions were provided in the home, nursing home, or by telehealth.

Community home-based interventions $(n=10)$ made up over half of the primary non-specialist interventions (8-10,14,15,18,20-22,24). These interventions were performed by nurses or other healthcare providers, including occupational and mental health therapists. Primary care physicians were consulted, but often were not directly involved with the intervention. There were varying time periods for the interventions and included both home visits and telephone visits. The focus was on education and holistic assessment, which includes physical, psychological, social, emotional, and spiritual symptoms.

The ambulatory clinic interventions $(n=7)$ used both nurses and a team approach to provide assessment and education for patients $(11-13,16,17,19,23)$. The frequency of visits ranged from one clinic visit up to ten clinic and phone combination visits.

\section{Specialist provider interventions}

Specialist provider interventions included interventions by a specialty trained or board certified palliative care member or the specialist team (7). Of the nine studies that tested specialist provider interventions most included cancer patients $(n=7)$ while two included patients with multiple diagnoses (25-33). The subcategories include community home-based $(\mathrm{n}=2)(23,24)$, inpatient $(\mathrm{n}=2)(27,30)$, and ambulatory clinic locations $(\mathrm{n}=5)(25,26,28,29,31)$.

The specialist community home-based intervention included two studies that were led by palliative care nurse specialists $(25,26)$. The interventions include assessment and education by a telehealth intervention. The participants received monthly follow-up after the educational sessions. Only one intervention identified the setting as being rural and the intervention itself was conducted using a telehealth method (23).

The two inpatient interventions included a team-based approach with follow-up at ambulatory clinics or by phone $(29,32)$. The included interventions focused on assessment, education, and advanced care planning. One study included a 24-hour on call service for symptom management (31).

Over half of the specialist provider interventions $(27,28,30,31,33)$ included ambulatory clinic visits. These were characterized by a team approach to care in the clinic setting and a specified time period between visits. The focus was assessment, education, and advanced care planning.

\section{Hybrid specialist-primary interventions}

Hybrid specialist-primary interventions $(\mathrm{n}=12)$ were defined as models that used a combination of specialist palliative care practitioners and specially-trained generalists (primary care providers). Of the 12 studies that tested hybrid specialist-primary interventions most were for patients with multiple diagnoses $(n=5)$ or heart failure $(n=4)$, and there was one each for patients with dementia/Alzheimer's $(\mathrm{n}=1)$, multiple sclerosis $(\mathrm{n}=1)$, and cancer $(\mathrm{n}=1)(34-45)$ The subcategories include community home-based $(n=4)$ $(33,39,41,43)$, inpatient $(\mathrm{n}=7)(32,34,36-38,40,42)$, and ambulatory clinic locations $(\mathrm{n}=1)(35)$.

In the four community home-based interventions a focus on team communication among palliative care providers and the primary care team was prominent $(35,41,43,45)$. Patients assessment and education were provided by palliative care providers using home visits and telephone follow-up.

Most of the hybrid specialist-primary models were inpatient $(n=7)(34,36,38-40,42,44)$. The palliative care team consulted with the primary healthcare teams after the initial visit to make recommendations and create a plan of care. Discharge planning and advance care planning discussions were a focus of the palliative care interventions.

Only one hybrid model was in an ambulatory clinic (35) for patients with a diagnosis of multiple sclerosis. Involvement from both the palliative care team and neurology assisted patients with management of symptoms and advanced care planning (37).

\section{Discussion}

There is a growing integration of palliative care services; however there are also multiple variations of models being tested in terms of who provides the care, when it is provided, for which diagnoses and when in the disease process the services are provided (e.g., at the time of or later in the diagnosis of the serious illness). In this review, of 38 published interventions, a variety of models were identified that included multiple providers and intervention locations. Primary non-specialist interventions provided evidence that with proper education of generalists, palliative care discussions and education can be initiated for patients with life limiting illnesses. Specialist provider interventions offer an opportunity for early palliative care access and discussions with both patients and families, including focused assessments and specialized treatments if needed. 
Hybrid specialist-primary interventions offer a team approach, collaboration, and continuity of care for patients and families. Despite growth and the variety of models there continues to be barriers and challenges such as gatekeeping, limited provider education, reimbursement, limited access for certain populations, as well as opportunities such as increased hospice use and better patient end-of-life care with early access to palliative care.

\section{Challenges and barriers to program $/$ model implementation}

\section{Gatekeeping and education}

Surveys that included healthcare providers found that palliative care is associated with terms that are synonymous with hospice services and end of life (46). The terms both evoked negative perceptions and stigma and were associated with the terms of death, hopelessness, dependency, and end-of-life care (46). This misconception has resulted in decreased use of palliative care services, especially early intervention palliative care (33). Unfortunately, this misconception causes patients and clinicians to avoid using potentially beneficial services because many believe these services are useful only when the patient is at the very endof-life.

Education on palliative care is needed in the primary healthcare field. This would assist with decreasing the risk of gatekeeping from possible beneficial interventions. There are programs that train physicians and nurses in palliative care $(47,48)$. Also, the Palliative Care and Hospice Education and Training Act has been reintroduced to U.S. House of Representative and U. S. Senate (49). This act would introduce workforce training for physicians, nurses, other healthcare providers (49).

\section{Reimbursement}

The Centers for Medicare and Medicaid Services have a special bundled payment method that can be used to provide hospice services for patients with a terminal illness and a life expectancy of 6 months or less (50). There is not a specially-designated payment system for palliative care services and this limits palliative care provision across settings. There is a growing awareness of the benefits of palliative care services among payers and policymakers, but the payment system remains a limitation for the expansion of palliative care. Morrison (51) found that the health care costs of patients in U. S. hospitals who received palliative care services was significantly less than the health care costs of patients that received usual care. The cost savings for patients alive at the time of discharge was $\$ 1,696$ per stay and $\$ 4,908$ per stay for patients that died during the hospitalization (51).

\section{Access}

Hospital palliative care programs are growing. According to CAPC, palliative care programs in hospitals with greater than 50 beds climbed from $53 \%$ in 2008 to $67 \%$ in 2015 (52). According to the CAPC State-by-State report card, one third of states remain at a grade of a C or D (A is the best; $\mathrm{F}$ is failing) (50). Rural access to palliative care remains limited; these same states also encompass a large portion of rural communities that are lacking access (50). This disparity is also seen in the limited literature available related to rural palliative care (53). Some of the models in this review used telehealth as one innovation to address the need to reach rural and underserved patients who would otherwise have to travel long distances to receive palliative care services.

\section{Benefits/opportunities of non-hospice palliative care}

\section{Increased hospice use and referrals}

There remains a consistent pattern of late referral to hospice for patients who are eligible (54). This leads to decreased benefits for patients and caregivers at end-of-life. However, studies have identified that palliative care services act as a transition for patients to hospice care in a timelier manner (55). The development of non-hospice palliative care models may assist in developing clear transitions for patients with life limiting illness and their families resulting in higher quality end-of-life care.

\section{Conclusions}

The increasing aging and chronic disease populations will require creative disease management and this is where non-hospice palliative care will be of benefit. Continued research is needed to find the most cost effective models of care for all patients with serious, chronic illnesses who can benefit from all that palliative care has to offer. This 
will require funding and evaluation of the best way to scale and disseminate/implement these services to multiple populations.

\section{Acknowledgements}

Funding: Dr. Bakitas receives research support from the National Institute for Nursing Research (1 R01 NR013665$01 \mathrm{~A} 1)$ and Dr. Kavalieratos receives research support from the National Heart, Lung, and Blood Institute (K01HL133466) and the Cystic Fibrosis Foundation.

\section{Footnote}

Conflicts of Interest: The authors have no conflicts of interest to declare.

\section{References}

1. Applequist H, Daly BJ. Palliation: A concept analysis. Res Theory Nurs Pract 2015;29:297-305.

2. Center to Advanced Palliative Care. What is palliative care? 2017. Available online: https://www.capc.org/payerspolicymakers/what-is-palliative-care/

3. American Cancer Society. Palliative or supportive care. 2014. Available online: https://www.cancer.org/treatment/ treatments-and-side-effects/palliative-care.html

4. American Cancer Society. What is hospice care? 2016. Available online: https://www.cancer.org/treatment/ finding-and-paying-for-treatment/choosing-yourtreatment-team/hospice-care/what-is-hospice-care.html

5. Kelley AS, Meier DE. Palliative care--a shifting paradigm. N Engl J Med 2010;363:781-2.

6. Kavalieratos D, Corbelli J, Di Z, et al. Association between palliative care and patient and caregiver outcomes: a systematic review and meta-analysis. JAMA 2016;316:2104-14.

7. von Gunten CF. Secondary and tertiary palliative care in US hospitals. JAMA 2002;287:875-81.

8. Aiken LS, Butner J, Lockhart CA, et al. Outcome evaluation of a randomized trial of the PhoenixCare intervention: program of case management and coordinated care for the seriously chronically ill. J Palliat Med 2006;9:111-26.

9. Bekelman DB, Plomondon ME, Carey EP, et al. Primary results of the patient-centered disease management (PCDM) for heart failure study: a randomized clinical trial. JAMA Intern Med 2015;175:725-32.
10. Chapman DG, Toseland RW. Effectiveness of advanced illness care teams for nursing home residents with dementia. Soc Work 2007;52:321-9.

11. Clark MM, Rummans TA, Atherton PJ, et al. Randomized controlled trial of maintaining quality of life during radiotherapy for advanced cancer. Cancer 2013;119:880-7.

12. Dyar S, Lesperance $M$, Shannon R, et al. A nurse practitioner directed intervention improves the quality of life of patients with metastatic cancer: results of a randomized pilot study. J Palliat Med 2012;15:890-5.

13. Engelhardt JB, McClive-Reed KP, Toseland RW, et al. Effects of a program for coordinated care of advanced illness on patients, surrogates, and healthcare costs: a randomized trial. Am J Manag Care 2006;12:93-100.

14. Farquhar MC, Prevost AT, McCrone P, et al. Is a specialist breathlessness service more effective and cost-effective for patients with advanced cancer and their carers than standard care? Findings of a mixed-method randomised controlled trial. BMC Med 2014;12:194.

15. Farquhar MC, Prevost AT, McCrone P, et al. The clinical and cost effectiveness of a Breathlessness Intervention Service for patients with advanced non-malignant disease and their informal carers: mixed findings of a mixed method randomised controlled trial. Trials 2016;17:185.

16. Given B, Given CW, McCorkle R, et al. Pain and fatigue management: results of a nursing randomized clinical trial. Oncol Nurs Forum 2002;29:949-56.

17. Lowther K, Selman L, Simms V, et al. Nurse-led palliative care for HIV-positive patients taking antiretroviral therapy in Kenya: a randomised controlled trial. Lancet HIV 2015;2:e328-34.

18. McCorkle R, Benoliel JQ, Donaldson G, et al. A randomized clinical trial of home nursing care for lung cancer patients. Cancer 1989;64:1375-82.

19. McCorkle R, Jeon S, Ercolano E, et al. An advanced practice nurse coordinated multidisciplinary intervention for patients with late-stage cancer: a cluster randomized trial. J Palliat Med 2015;18:962-9.

20. Northouse L, Kershaw T, Mood D, et al. Effects of a family intervention on the quality of life of women with recurrent breast cancer and their family caregivers. Psychooncology 2005;14:478-91.

21. Northouse LL, Mood DW, Schafenacker A, et al. Randomized clinical trial of a brief and extensive dyadic intervention for advanced cancer patients and their family caregivers. Psychooncology 2013;22:555-63.

22. Northouse LL, Mood DW, Schafenacker A, et al. Randomized clinical trial of a family intervention for 
prostate cancer patients and their spouses. Cancer 2007;110:2809-18.

23. Rummans TA, Clark MM, Sloan JA, et al. Impacting quality of life for patients with advanced cancer with a structured multidisciplinary intervention: a randomized controlled trial. J Clin Oncol 2006;24:635-42.

24. Steel JL, Geller DA, Kim KH, et al. Web-based collaborative care intervention to manage cancerrelated symptoms in the palliative care setting. Cancer 2016;122:1270-82.

25. Bakitas M, Lyons KD, Hegel MT, et al. Effects of a palliative care intervention on clinical outcomes in patients with advanced cancer: the Project ENABLE II randomized controlled trial. JAMA 2009;302:741-9.

26. Bakitas MA, Tosteson TD, Li Z, et al. Early versus delayed initiation of concurrent palliative oncology care: patient outcomes in the ENABLE III randomized controlled trial. J Clin Oncol 2015;33:1438-45.

27. Groenvold M, Petersen MA, Damkier A, et al. Randomised clinical trial of early specialist palliative care plus standard care versus standard care alone in patients with advanced cancer: The Danish Palliative Care Trial. Palliat Med 2017;31:814-24.

28. Rabow MW, Dibble SL, Pantilat SZ, et al. The comprehensive care team: a controlled trial of outpatient palliative medicine consultation. Arch Intern Med 2004;164:83-91.

29. Rogers JG, Patel CB, Mentz RJ, et al. Palliative care in heart failure: the PAL-HF randomized, controlled clinical trial. J Am Coll Cardiol 2017;70:331-41.

30. Temel JS, Greer JA, El-Jawahri A, et al. Effects of early integrated palliative care in patients with lung and GI cancer: a randomized clinical trial. J Clin Oncol 2017;35:834-41.

31. Temel JS, Greer JA, Muzikansky A, et al. Early palliative care for patients with metastatic non-small-cell lung cancer. N Engl J Med 2010;363:733-42.

32. Wallen GR, Baker K, Stolar M, et al. Palliative care outcomes in surgical oncology patients with advanced malignancies: a mixed methods approach. Qual Life Res 2012;21:405-15

33. Zimmermann C, Swami N, Krzyzanowska M, et al. Early palliative care for patients with advanced cancer: a clusterrandomised controlled trial. Lancet 2014;383:1721-30.

34. Ahronheim JC, Morrison RS, Morris J, et al. Palliative care in advanced dementia: a randomized controlled trial and descriptive analysis. J Palliat Med 2000;3:265-73.

35. Brannstrom M, Boman K. Effects of person-centred and integrated chronic heart failure and palliative home care. PREFER: a randomized controlled study. Eur J Heart Fail 2014;16:1142-51.

36. Cheung W, Aggarwal G, Fugaccia E, et al. Palliative care teams in the intensive care unit: a randomised, controlled, feasibility study. Crit Care Resusc 2010;12:28-35.

37. Edmonds P, Hart S, Wei G, et al. Palliative care for people severely affected by multiple sclerosis: evaluation of a novel palliative care service. Mult Scler 2010;16:627-36.

38. Gade G, Venohr I, Conner D, et al. Impact of an inpatient palliative care team: a randomized control trial. J Palliat Med 2008;11:180-90.

39. Grudzen CR, Richardson LD, Johnson PN, et al. Emergency department-initiated palliative care in advanced cancer: a randomized clinical trial. JAMA Oncol 2016. [Epub ahead of print].

40. Hanks GW, Robbins M, Sharp D, et al. The imPaCT study: a randomised controlled trial to evaluate a hospital palliative care team. Br J Cancer 2002;87:733-9.

41. Higginson IJ, Bausewein C, Reilly CC, et al. An integrated palliative and respiratory care service for patients with advanced disease and refractory breathlessness: a randomised controlled trial. Lancet Respir Med 2014;2:979-87.

42. Hopp FP, Zalenski RJ, Waselewsky D, et al. Results of a hospital-based palliative care intervention for patients with an acute exacerbation of chronic heart failure. J Card Fail 2016;22:1033-6.

43. Radwany SM, Hazelett SE, Allen KR, et al. Results of the promoting effective advance care planning for elders (PEACE) randomized pilot study. Popul Health Manag 2014;17:106-11.

44. Sidebottom AC, Jorgenson A, Richards H, et al. Inpatient palliative care for patients with acute heart failure: outcomes from a randomized trial. J Palliat Med 2015;18:134-42.

45. Wong FK, Ng AY, Lee PH, et al. Effects of a transitional palliative care model on patients with end-stage heart failure: a randomised controlled trial. Heart 2016;102:1100-8.

46. Dai YX, Chen TJ, Lin MH. Branding palliative care units by avoiding the terms "Palliative" and "Hospice". Inquiry 2017;54:46958016686449.

47. Emanuel LL, Ferris FD, von Gunten CF. EPEC. Education for Physicians on End-of-Life Care. Am J Hosp Palliat Care 2002;19:17; author reply -8.

48. Ferrell B, Malloy P, Virani R. The End of Life Nursing Education Nursing Consortium project. Ann Palliat Med 
2015;4:61-9.

49. Alzheimer's Association. Palliative care and hospice education and training act. 2017. Available online: http:// act.alz.org/site/PageServer?pagename=PCHETA

50. Center for Medicaid and Medicare Services. Hospice2016. Available online: https://www.cms.gov/Center/ProviderType/Hospice-Center.html

51. Morrison RS, Penrod JD, Cassel JB, et al. Cost savings associated with US hospital palliative care consultation programs. Arch Intern Med 2008;168:1783-90.

52. Center to Advanced Palliative Care. America's care of serious illness: 2015 state-by-state report card on access to palliative care in our nation's hospitals. 2015.

Cite this article as: Beasley A, Bakitas MA, Edwards R, Kavalieratos D. Models of non-hospice palliative care: a review. Ann Palliat Med 2019;8(Suppl 1):S15-S21. doi: 10.21037/ apm.2018.03.11
Available online: https://reportcard.capc.org/wp-content/ uploads/2015/08/CAPC-Report-Card-2015.pdf

53. Bakitas MA, Elk R, Astin M, et al. Systematic review of palliative care in the rural setting. Cancer Control 2015;22:450-64.

54. National Hospice and Palliative Care Organization. Facts and figures: Hospice care in America. 2016. Available online: https://www.nhpco.org/sites/default/files/public/ Statistics_Research/2016_Facts_Figures.pdf

55. Riggs A, Breuer B, Dhingra L, et al. Hospice enrollment after referral to community-based, specialist-level palliative care: incidence, timing, and predictors. J Pain Symptom Manage 2016;52:170-7. 